\title{
Computational Complexity Reduction of OFDM Signals by PTS with Alternate Optimized Recursive Phase Weighting (AO-RPW) Method
}

\author{
Prashant Pandey \\ Member IEEE \\ Department of Electronics and \\ Communication, Motilal Nehru \\ National Institute of \\ Technology,Allahabad
}

\author{
Rajeev Tripathi \\ Member IEEE \\ Department of Electronics and \\ Communication, Motilal Nehru \\ National Institute of \\ Technology,Allahabad
}

\begin{abstract}
Partial transmit sequences (PTS) is one of the most attractive schemes to reduce the peak-to-average power ratio (PAPR) in orthogonal frequency division multiplexing (OFDM) systems. However, the Optimal PTS (OPTS) scheme requires an exhaustive searching over all combinations of allowed phase factors. Consequently, the computational complexity increases exponentially with the number of the subblocks. Recursive phase weighting (RPW) technique is a novel method whose aim is to reduce computational complexity and achieve the same performance in PAPR reduction as compared to O-PTS. In this paper we have proposed a novel technique named as Alternate optimized Recursive phase weighting (AO-RPW) method. Theoretical analysis and simulation results show that, compared with O-PTS and PTS employing RPW, PTS with AO-RPW method reduces the computational complexity but at the cost of loss of performance for PAPR reduction.
\end{abstract}

\section{General Terms}

Orthogonal Frequency Division Multiplexing (OFDM) System

\section{Keywords}

Complimentary cumulative distribution function (CCDF), Partial Transmit Sequence (PTS), Peak-to-average power ratio (PAPR)

\section{INTRODUCTION}

Orthogonal frequency division multiplexing [1], [2] is a promising technique that provides high spectral efficiency for next-generation broadband wireless systems. It has gained popularity in a number of applications including digital audio broadcasting (DAB), terrestrial digital video broadcasting (DVB-T), the IEEE 802.11a standard for wireless local area networks (WLAN) and the IEEE 802.16d standard for wireless metropolitan area networks (WMAN), owing to its high bandwidth efficiency and robustness to multipath fading. However, there remains some drawbacks in OFDM systems such as high peak-to-average power ratio. It may result in significant distortion when the transmitted signals is passed through a nonlinear device such as the power amplifier [3].In order to reduce PAPR many PAPR reduction schemes have been proposed in the literature such as as clipping and filtering [5]-[8], partial transmit sequence [9]-[16], selected mapping [17]-[23], coding schemes [24]-[28], nonlinear companding transforms [29]-[31], tone reservation (TR) and tone injection (TI) [32]-[33]. Among all existing schemes, partial transmit sequences (PTS) [34] is an important technique because of its good PAPR reduction performance without any signal distortion.

In this paper, we propose a phase weighting method for PTS, named as alternate optimized recursive phase weighting method [34], [36]-[37]. Its aim is to reduce the computational complexity compared to O-PTS and PTS with RPW. However the proposed scheme has some loss in PAPR reduction performance.

This paper is organised as follows. In Section 2, we present the PAPR in OFDM system. In Section 3, we have described optimal PTS and recursive phase weighting method for PTS. Section 4 introduces proposed alternate optimized recursive phase weighting (AO-RPW) method for PTS. In section 5, the performance of proposed phase weighting method is discussed and the simulation and numerical results are shown. Finally, we end the paper with brief conclusions in Section 6 .

\section{The PAPR IN OFDM SYSTEM}

In OFDM system, a block of $N$ symbols $X=\left\{X_{k}, k=0,1\right.$, ...., N-1 $\}^{\mathrm{T}}$ is formed with each symbol modulating one of a set of subcarriers, $\left\{\mathrm{f}_{\mathrm{k}}, \mathrm{k}=0,1,2, \ldots \ldots \ldots, \mathrm{N}-1\right\}$ where $\mathrm{N}$ is the number of subcarriers. The $\mathrm{N}$ subcarriers are chosen to be orthogonal, i.e. $f_{k}=k \Delta f$ where $\Delta f=1 /(N T)$ and $T$ is the original symbol period. Now, the complex envelope of the transmitted OFDM signals can be written as,

$$
\mathrm{x}(\mathrm{t})=\frac{1}{\sqrt{\mathrm{N}}} \sum_{\mathrm{k}=0}^{\mathrm{N}-1} \mathrm{X}_{\mathrm{k}} \mathrm{e}^{\mathrm{j} 2 \pi \mathrm{f}_{\mathrm{k}} \mathrm{t}}, 0 \leq \mathrm{t} \leq \mathrm{NT}
$$

where $\mathrm{j}=\sqrt{-1}$

In general, the PAPR of OFDM signals $x(t)$ is defined as the ratio of the maximum instantaneous power and its average power

$$
\operatorname{PAPR}[\mathrm{x}(\mathrm{t})]=\frac{0 \leq \mathrm{max} \mathrm{NT}^{\left[|\mathrm{x}(\mathrm{t})|^{2}\right.}}{\mathrm{P}_{\mathrm{av}}}
$$

Where $\mathrm{P}_{\mathrm{av}}$ is the average power of $x(t)$ and is given by:

$\mathrm{P}_{\mathrm{av}}=\frac{1}{\mathrm{NT}} \int_{0}^{\mathrm{NT}}|\mathrm{x}(\mathrm{t})|^{2} \mathrm{dt}$

The complementary cumulative distribution function (CCDF) of the PAPR is the most frequently used performance measure for PAPR reduction techniques. The CCDF of the PAPR denotes the probability that the PAPR of a data block exceeds a given threshold $\gamma$. When the number of the subcarriers $N$ is 
relatively small, the CCDF expression of the PAPR of OFDM signals can be expressed as

$$
\operatorname{Prob}\{\text { PAPR }>\gamma\}=1-\left(1-\mathrm{e}^{-\gamma}\right)
$$

\section{OPTIMAL PTS (O-PTS) And RPW For PTS}

\subsection{The PTS Technique}

In PTS, as shown in fig. 1, an input data block of $\mathrm{N}$ symbols is partitioned into $\mathrm{M}$ disjoint subblocks, which are transformed into $\mathrm{M}$ time-domain partial transmit sequences. These partial sequences are independently rotated by phase factors. The objective of this approach is to optimally combine the subblocks to obtain the time domain OFDM signals with the lowest PAPR.

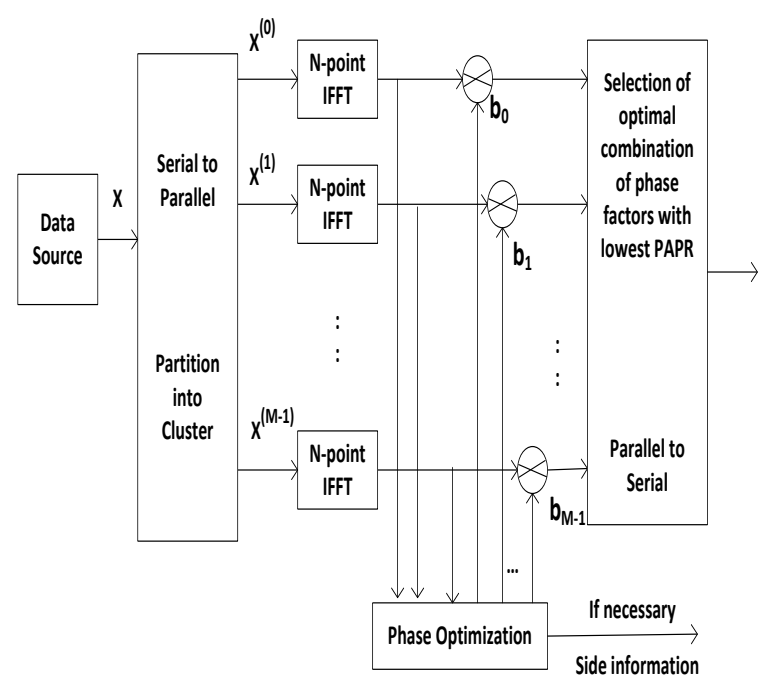

Figure 1: Block Diagram of the PTS Technique

\subsection{Mathematical Model for the O-PTS \\ Technique}

In O-PTS, the input data sequence of an OFDM system with $\mathrm{N}$ subcarriers is firstly partitioned into $\mathrm{M}$ disjoint subblocks $\mathrm{X}_{\mathrm{i}}, \mathrm{i}=1,2, \ldots, \mathrm{M}$, where all the subcarriers which are occupied by the other subblocks are set to zero. The frequency domain input sequence is given as

$$
X=\sum_{i=1}^{M} X_{i}
$$

By applying a phase weighting factor $\mathrm{b}_{\mathrm{i}}=\exp \left(\mathrm{j} \Phi_{\mathrm{i}}\right), \Phi_{\mathrm{i}} \epsilon[0$, $2 \pi)$ to the $i^{\text {th }}$ subblock $X_{i}=\left[X_{i, 1}, X_{i, 2}, \ldots \ldots \ldots, X_{i, N}\right]^{\mathrm{T}}, i=1,2$, ......, $\mathrm{M}$, alternative frequency signal sequence is given as

$$
\mathrm{X}^{\prime}=\sum_{\mathrm{i}=1}^{\mathrm{M}} \mathrm{b}_{\mathrm{i}}
$$

After being transformed to time domain by IFFT, the time domain signal sequence becomes

$$
x^{\prime}=\operatorname{IFFT}\left\{\sum_{i=1}^{M} b_{i} X_{i}\right\}=\sum_{i=1}^{M} b_{i} \text { IFFT }\left\{X_{i}\right\}=\sum_{i=1}^{M} b_{i} x_{i}
$$

In the above equation, $\mathbf{x}^{\prime}$ denotes the candidate sequence.

For generating different phase weighting sequences, a set of phase weighting factors is normally chosen. Assuming that there be $\mathrm{W}$ allowed phase weighting factors in this set, without any loss of performance, we can set phase weighting factor for the first subblock to one and we see that there are (M-1) subblocks to be optimized. It is obvious that $\mathrm{W}^{\mathrm{M}-1}$ combinations must be checked to find the optimum candidate sequence with the minimum PAPR. For optimal PTS (OPTS), the optimum PAPR performance can be got after searching $\mathrm{W}^{\mathrm{M}-1}$ possible alternative combinations where $\mathrm{M}$ is the number of subblocks and $\mathrm{W}$ is the number of allowed phase weighting factors. In the process of phase weighting combination, large number of complex multiplications are needed and hence the computational complexity is very large.

\subsection{Recursive Phase Weighting for PTS}

As above mentioned, there are $\mathrm{W}^{\mathrm{M}-1}$ phase weighting sequences generated for obtaining candidate sequences. Considering all the phase weighting sequences, we can find the relationship (which will be mentioned in the observation later) between phase weighting sequences if the following conditions are satisfied: i) The number of phase weighting factors $\mathrm{W}$ is even; ii) The set of allowed phase weighting factors is $\left\{\mathrm{e}^{\mathrm{j}(2 \pi \mathrm{k} / \mathrm{W})}, \mathrm{k}=0,1, \ldots \ldots, \mathrm{W}-1\right\}$. Under the aforementioned conditions, we can have an important observation as follows.

Observation: For any one from all the phase weighting sequences, there exists the other one such that in the corresponding positions of these two sequences, some phase weighting factors are opposite and the rest ones are same.

The relationships among phase weighting sequences can be recursively continued to reduce computational complexity. Thus, PTS with RPW has low computational complexity as compared to O-PTS.

\section{ALTERNATE OPTIMISED RECURSIVE PHASE WEIGHTING (AO- RPW) METHOD}

In this proposed approach alternate optimization is used with recursive phase weighting method e.g. When the no. of subblocks $M=4$ and the set of phase weighting factors is $\{1$, 1) (i.e $W=2$ ), all the phase weighting factor sequences, identified by $\mathrm{B}_{1}, \mathrm{~B}_{2}, \ldots . ., \mathrm{B}_{8}$ (for RPW) are shown in Table 1 while those identified by $\mathrm{B}_{1}, \mathrm{~B}_{2}, \ldots, \mathrm{B}_{4}$ (for AO-RPW) are shown in Table 2.

Table 1

All The Phase Weighting Sequences for $W=2$ and $M=4$ (for RPW)

\begin{tabular}{|l|r|c|c|}
\hline & $\begin{array}{l}\text { Phase Weighting } \\
\text { Sequence }\end{array}$ & $\begin{array}{l}\text { Phase Weighting } \\
\text { Sequence }\end{array}$ \\
\hline $\mathrm{B}_{1}$ & {$[1,1,1,1]$} & $\mathrm{B}_{5}$ & {$[1,-1,-1,-1]$} \\
\hline $\mathrm{B}_{2}$ & {$[1,1,1,-1]$} & $\mathrm{B}_{6}$ & {$[1,-1,-1,1]$} \\
\hline $\mathrm{B}_{3}$ & {$[1,1,-1,1]$} & $\mathrm{B}_{7}$ & {$[1,-1,1,-1]$} \\
\hline $\mathrm{B}_{4}$ & {$[1,1,-1,-1]$} & $\mathrm{B}_{8}$ & {$[1,-1,1,1]$} \\
\hline
\end{tabular}


Table 2

All The Phase Weighting Sequences for $W=2$ and $M=4$ (forAO-RPW)

\begin{tabular}{|c|c|}
\hline & Phase Weighting Sequence \\
\hline $\mathrm{B}_{1}$ & {$[1,1,1,1]$} \\
\hline $\mathrm{B}_{2}$ & {$[1,1,-1,1]$} \\
\hline $\mathrm{B}_{3}$ & {$[1,-1,-1,-1]$} \\
\hline $\mathrm{B}_{4}$ & {$[1,-1,1,-1]$} \\
\hline
\end{tabular}

From the above two tables we conclude that in RPW we have 8 phase weighting sequences while in AO-RPW we have 4 phase weighting sequences. Thus computational complexity is obviously reduced in AO-RPW as compared to RPW but at the cost of PAPR reduction performance.

\section{PERFORMANCE ANALYSIS AND SIMULATION RESULTS}

\subsection{Performance Analysis}

The advantage in AO-RPW is that it has lesser computational complexity than RPW and O-PTS but the disadvantage is that it has lesser PAPR reduction capability than RPW and O-PTS.

\subsection{Simulation Results}

In this section, we do extensive simulations to verify the performance of the proposed schemes. For our simulation the above parameters (table 3 ) have been used.
Table 3 : Simulation Parameters

\begin{tabular}{|l|l|}
\hline $\begin{array}{l}\text { Number of OFDM blocks for } \\
\text { iteration }\end{array}$ & 3000 \\
\hline No. of Subcarriers (N) & $128,256,512$ \\
\hline No. of disjoint subblocks (M) & 4 \\
\hline Oversampling factor (L) & 4 \\
\hline Modulation type & QPSK \\
\hline No. of phase weighting factors & 2 \\
\hline The set of phase weighting factors & $\{1,-1\}$ \\
\hline
\end{tabular}

For PAPR reduction performance, the CCDF is used to evaluate and compare the performance of any PAPR reduction schemes. Figure 2, 3 and 4 show performance comparison between the original OFDM, AO-RPW method and RPW method. As is Obvious from the figures AO-RPW method has lesser PAPR reduction capability than that of the RPW method which is the disadvantage as stated in the theoretical analysis. Also it is evident from the figures that PAPR reduction capability decreases as we increase the number of subcarriers.

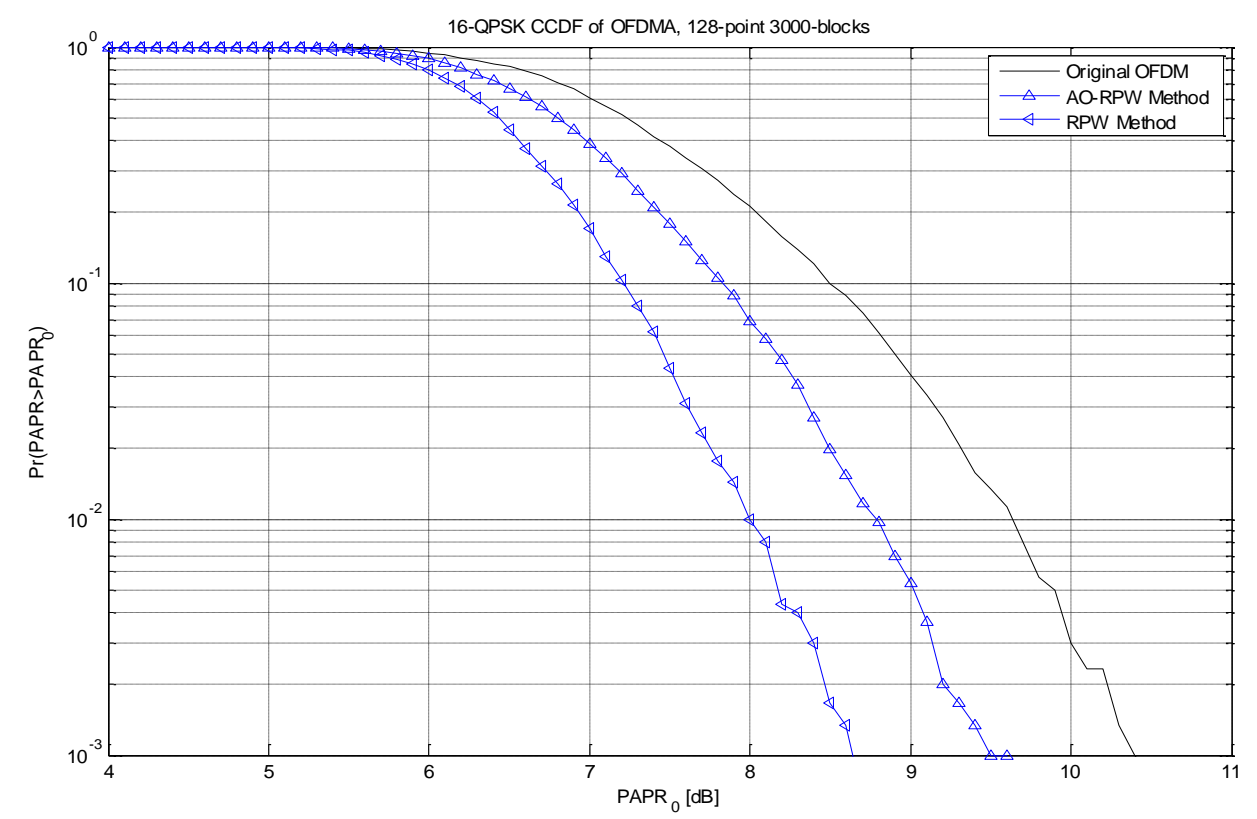

Figure 2: Comparison of CCDF of PAPR of PTS with AO-RPW, RPW and Original OFDM Signal (N=128) 


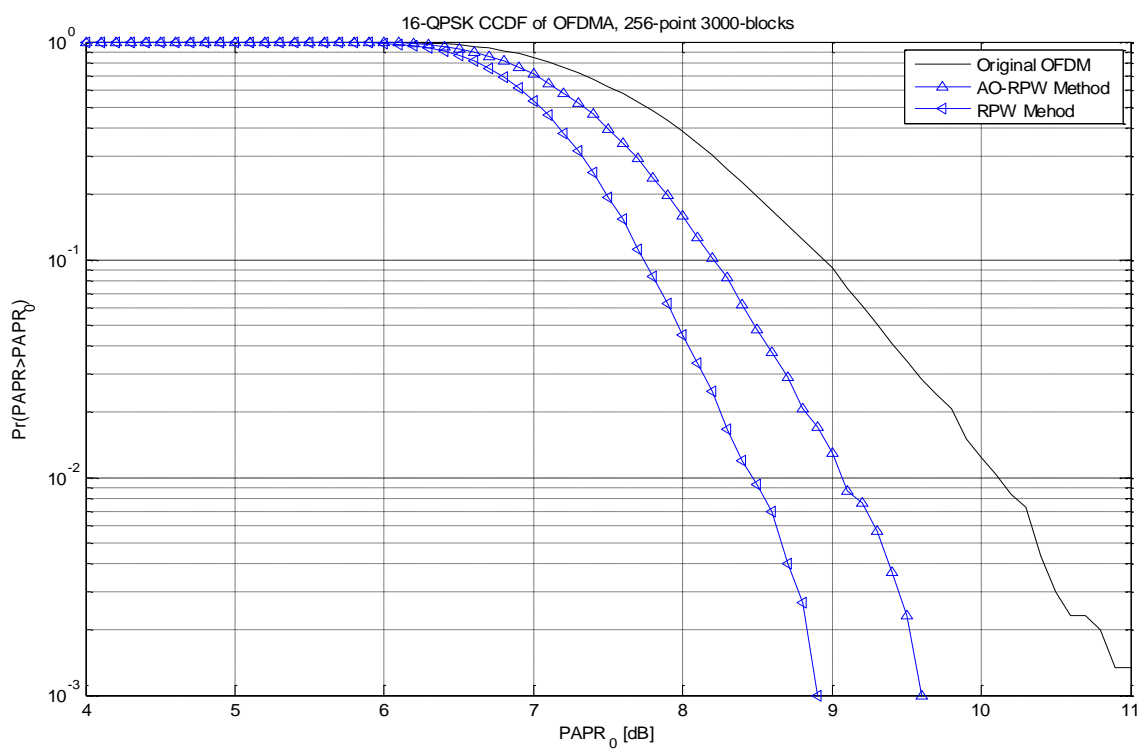

Figure 3: Comparison of CCDF of PAPR of PTS with AO-RPW, RPW and Original OFDM Signal (N=256)

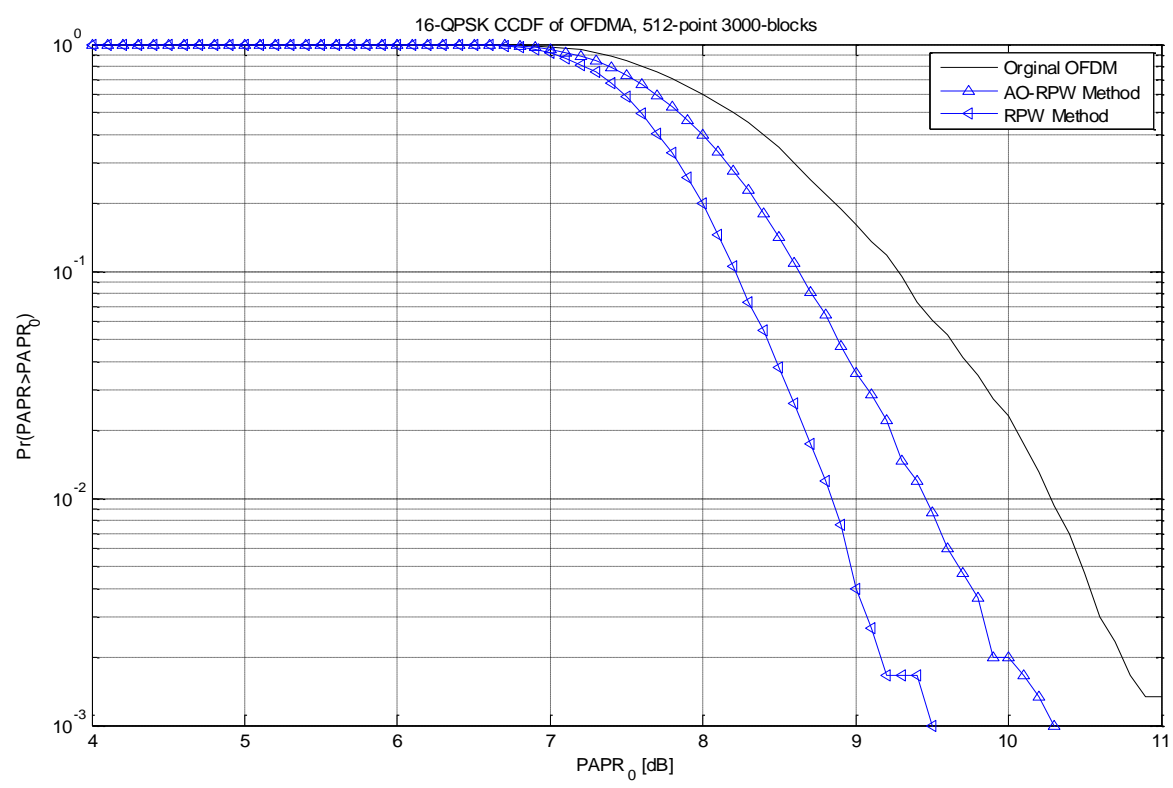

Figure 4: Comparison of CCDF of PAPR of PTS with AO-RPW, RPW and Original OFDM Signal (N=512)

\section{CONCLUSIONS}

In this paper, a phase weighting method with low computational complexity for PTS is proposed. This method (AO-RPW) has lesser computational complexity as compared to existing methods viz. RPW and O-PTS. However it has the drawback that its PAPR reduction capability is lesser as compared to GPW method and the advantage that PAPR reduction capability is greater than that of O-PTS Method. Hence the computational complexity is reduced but at the cost of PAPR reduction performance.

\section{REFERENCES}

[1] Wu Y. and Zou W. Y., "Orthogonal frequency division multiplexing: A multi-carrier modulation scheme," IEEE Trans. Consum. Electron., vol. 41, no. 3, pp. 392-399, Aug. 1995.

[2] Zou W. Y. and Wu Y., "COFDM: An overview," IEEE Trans. Broadcast., vol. 41, no. 1, pp. 1-8, Mar. 1995.

[3] Hou J., Ge J., and Li J., "Peak-to-Average Power Ratio Reduction of OFDM Signals Using PTS Scheme With Low Computational Complexity," IEEE Trans. on Broad., Vol. 57, No. 1, Mar. 2011, pp. 143-148. 
[4] Neill R. O' and Lopes L. N. "Envelope variations and spectral splatter in clipped multicarrier signals," in Proc. PMRC'95, Sept. 1995, pp. 71-75.

[5] Ochiai H. and Imai H., "Performance analysis of deliberately clipped OFDM signals," IEEE Trans. Commun., Jan. 2002, 50, (1), pp. 89-101.

[6] Ju S. M. and Leung S. H., "Clipping on COFDM with phase on demand," IEEE Communications Letters, Feb. 2003, 7, (2), pp. 49-51.

[7] Ren G. L., Zhang H., and Chang Y. L., "A complementary clipping transform technique for the reduction of peak-to-average power ratio of OFDM system," IEEE Trans. Consumer Electronics, Nov. 2003, 49, (4), pp. 922-926.

[8] Muller S. H. and Huber J. B., "OFDM with reduced peak-to-average power ratio by optimum combination of partial transmit sequences," IEE Electronics Letters, Feb. 1997, 33, (5), pp. 36-69.

[9] Han S. H. and Lee J. H. "PAPR reduction of OFDM signals using a reduced complexity PTS technique," IEEE Signal Processing Letters, Nov. 2004, 11, (11), pp. 887-890.

[10] Alavi A., Tellambura C., and Fair I., "PAPR reduction of OFDM signals using partial transmit sequence: An optimal approach using sphere decoding," IEEE Trans. Communications Letters, Nov. 2005, 9, (11), pp. 982984

[11] Hieu N. T., Kim S. W., and Ryu H. G., "PAPR reduction of the low complexity phase weighting method in OFDM communication system," IEEE Trans. Consumer Electronics, Aug. 2005, 51, (3), pp. 776-782.

[12] Yang L., Chen R. S., Siu Y. M., and Soo K. K., "PAPR reduction of an OFDM signal by use of PTS with low computational complexity," IEEE Trans. Broadcasting, Mar. 2006, 52, (1), pp. 83-86.

[13] Chen H. and Liang H., "PAPR reduction of OFDM signals using partial transmit sequences and Reed-Muller codes," IEEE Communications Letters, Jun. 2007, 11, (6), pp. 528-530.

[14] Park D. H. and Song H. K. "A new PAPR reduction technique of OFDM system with nonlinear high power amplifier," IEEE Trans. Consumer Electronics, May 2007, 53, (2), pp. 327-332.

[15] Xiao Y., Lei X., Wen Q., and Li S., "A class of low complexity PTS techniques for PAPR reduction in OFDM systems," IEEE Signal Processing Letters, Oct. $2007,14,(10)$, pp. 680-683.

[16] Baxley R. J. and Zhou G. T., "Comparing selected mapping and partial transmit sequence for PAR reduction," IEEE Trans. Broadcasting, Dec. 2007, 53, (4), pp. 797-803.

[17] Heo S. J., Noh H. S., No J. S., and Shin D. J., “A modified SLM scheme with low complexity for PAPR reduction of OFDM systems," IEEE Trans. Broadcasting, Dec. 2007, 53, (4), pp. 804-808.

[18] Lim D. W. , No J. S., Lim C. W., and Chung H., "A new SLM OFDM scheme with low complexity for PAPR reduction," IEEE Signal Processing Letters, Feb. 2005, 12, (2), pp. 93-96.
[19] Wang C. L. and Yuan Q. Y., "Low-complexity selected mapping schemes for peak-to-average power ratio reduction in OFDM systems," IEEE Trans. Signal Processing, Dec. 2005, 53, (12), pp. 4652-4660.

[20] Ryu H. G., Hoa T. P. , Lee K. M. , Kim S. W., and Park J. S. "Improvement of power efficiency of HPA by the PAPR reduction and predistortion," IEEE Trans Consumer Electronics, Feb. 2004, 50, (1), pp. 119-124.

[21] Han S. H. and Lee J. H., "Modified selected mapping technique for PAPR reduction of coded OFDM signal," IEEE Trans. Broadcasting, 50, (3), pp. 335-341, Sept. 2004.

[22] Bauml R. W., Fisher R. F. H., and Huber J. B. "Reducing the Peak-to-Average Power Ratio of Multicarrier Modulation by Selected Mapping," IEE Electronics Letters, Oct. 1996, 32, (22), pp. 2056-2057.

[23] Jones A. E., Wilkinson T. A., and Barton S. K., "Block coding scheme for reduction of peak-to-average envelope power ratio of multicarrier transmission systems," IEE Electronics Letters, Dec. 1994, 30, (8), pp. 2098-2099.

[24] Fan P. Y. and Xia X. G., "Block coded modulation for the reduction of the peak to average power ratio in OFDM systems," IEEE Trans. Consumer Electronics, Nov. 1999, 45, (4), pp. 1025-1029.

[25] Yang K. and Chang S., "Peak-to-average power control in OFDM using standard arrays of linear block codes," IEEE Communications Letters, Apr. 2003, 7, (4), pp. 174-176.

[26] Jiang T. and Zhu G. X., "Complement block coding for reduction in peak-to-average power ratio of OFDM signals," IEEE Communications Magazine, Sept. 2005, 43, (9), pp. S17-S22.

[27] Slimane S. B., "Reducing the peak-to-average power ratio of OFDM signals through precoding," IEEE Trans. Vehicular Technology, Mar. 2007, 56, (2), pp. 686-695.

[28] Wang X. B., Tjhung T. T., and Ng C. S., "Reduction of peak-to-average power ratio of OFDM system using A companding technique," IEEE Trans. Broadcasting, Sept 1999, 45, (3), pp. 303-307.

[29] Jiang T. and Zhu G. X., "Nonlinear companding transform for reducing peak-to-average power ratio of OFDM signals," IEEE Trans. Broadcasting, Sept. 2004, 50, (3), pp. 342-346

[30] Huang X., Lu J. H., Zheng J. L., Letaief K. B., and Gu J., "Companding transform for reduction in peak-to-average power ratio of OFDM signals," IEEE Trans. Wireless Communications, Nov. 2004, 3, (6), pp. 2030-2039.

[31] Tellado J., "Peak to Average Power Ratio Reduction for Multicarrier Modulation," PhD thesis, University of Stanford, Stanford, 1999.

[32] Yoo S. S., Yoon S., Kim S. Y., and Song I., "A novel PAPR reduction scheme for OFDM systems: Selective mapping of partial tones (SMOPT)," IEEE Trans. Consumer Electronics, Feb. 2006, 52, (1), pp. 40-43.

[33] Wang L. and Liu J., "PAPR Reduction of OFDM Signals by PTS With Grouping and Recursive Phase Weighting methods," IEEE Trans. Broadcast., June 2011, 57, (2), pp. 1-8. 
[34] Wang L. and Cao Y., "Sub-optimum PTS for PAPR reduction of OFDM signals," Electron. Lett., vol. 44, no. 15, pp. 921-922, Jul. 2008

[35] Pandey P. and Tripathi R., "Performance analysis of peak-to-average power ratio (PAPR) reduction techniques in an OFDM system," in Third IEEE International conference on computer and communication technology (ICCCT), Allahabad, pp. 245-249, Nov. 2012.

[36] Pandey P. and Tripathi R., "Comparative Analysis of Peak-to-Average Power Ratio (PAPR) Reduction Techniques for OFDM System" in Fourth IEEE International conference on computer and communication technology (ICCCT), Allahabad, pp. 163-168, Sept. 2013.

[37] Pandey P. and Tripathi R., "Computational Complexity Reduction of OFDM Signals by PTS with Alternate Optimised Grouping Phase Weighting Method" International Journal of Computer Applications, Sept. 2013, 78, (1), pp. 1-7.

[38] [40] Pandey P. and Tripathi R., “ Computational Complexity and Peak-to-Average Power Ratio Reduction of OFDM Signals by PTS with Sub -optimum Grouping Phase Weighting Method" International Journal of Computer Applications, Oct. 2013, 79, (11), pp. 6-11. 